\title{
Framing the process in the implementation of care for people with generalized anxiety disorder in primary care: a qualitative evidence synthesis
}

Ana Toledo-Chávarri 1,2,3,4, Vanesa Ramos-García ${ }^{1,4^{*}}$ (D), Alezandra Torres-Castaño 1,4, María M Trujillo-Martín 1,2,3,4, Wenceslao Peñate Castro ${ }^{5}$, Isabel Del Cura-Castro ${ }^{2,6,7}$, Pedro Serrano-Aguilar ${ }^{2,3,4,8}$ and Lilisbeth Perestelo-Pérez ${ }^{2,3,4,8}$

\begin{abstract}
Background: Generalized anxiety disorder (GAD) is one of the most common mental disorders in primary care (PC). GAD has low remission and high relapse rates over long follow-up periods. Qualitative evidence was synthesized to understand the implementation of care and treatment options for people with GAD in PC.

Methods: Research published from 2008 to September 2020 was searched in five databases (MEDLINE, EMBASE, CINAHL, WOS and PsycArticles). Studies that used qualitative methods for data collection and analysis to investigate the implementation of care and treatment options for people with GAD in PC and outpatient settings were included. Non-qualitative studies, mixed methods studies that did not separately report qualitative findings and studies in languages other than English or Spanish were excluded. We used the Confidence in the Evidence from Reviews of Qualitative Research (CERQual) framework to assess the overall confidence in the findings.

Results: The results with a moderate level of confidence showed that the trajectory of care for people with GAD in PC and outpatient settings is long and fluctuates over time, involving multiple difficulties in accessing and maintaining initial treatment or successive treatment options. In addition, there are wide variations in the preferences for and acceptability of different treatment options. The results with a high level of confidence indicated that more information on GAD and its treatment options is needed for PC practitioners, GAD patients and their carers. The results with a low level of confidence suggested that patients use antidepressants for longer than recommended and that the interruption of treatment is not usually planned.

(Continued on next page)
\end{abstract}

\footnotetext{
* Correspondence: vanesa.ramosgarcia@sescs.es

${ }^{1}$ Canary Islands Health Research Institute Foundation, Tenerife, Spain

${ }^{4}$ The Spanish Network of Agencies for Health Technology Assessment and

Services of the National Health System (RedETS), Tenerife, Spain

Full list of author information is available at the end of the article
}

(C) The Author(s). 2020 Open Access This article is licensed under a Creative Commons Attribution 4.0 International License, which permits use, sharing, adaptation, distribution and reproduction in any medium or format, as long as you give appropriate credit to the original author(s) and the source, provide a link to the Creative Commons licence, and indicate if changes were made. The images or other third party material in this article are included in the article's Creative Commons licence, unless indicated otherwise in a credit line to the material. If material is not included in the article's Creative Commons licence and your intended use is not permitted by statutory regulation or exceeds the permitted use, you will need to obtain permission directly from the copyright holder. To view a copy of this licence, visit http://creativecommons.org/licenses/by/4.0/ The Creative Commons Public Domain Dedication waiver (http://creativecommons.org/publicdomain/zero/1.0/) applies to the data made available in this article, unless otherwise stated in a credit line to the data. 
(Continued from previous page)

Conclusions: Initial resistance to new treatments among people with GAD can make access and adherence to treatment difficult. Improving care may require patients to be informed of possible trajectories in stepped care pathways before the initiation of treatment so they are aware that they may need to try a number of options until the most effective treatment for them is found. Increased awareness of and information materials on GAD may facilitate both appropriate diagnosis and long-term care.

Keywords: Generalized Anxiety Disorder, Experiences and Patient Preferences, Primary Care, Qualitative Evidence Synthesis

\section{Background}

Epidemiological studies show that anxiety disorders (ADs) are the most common type of mental disorders in the European Union, with a 12-month prevalence of approximately $14 \%$ and 61.5 million persons affected [1], and are associated with a high burden of illness [1-3]. According to the data provided by the World Health Organization (WHO), more than 260 million people in the world currently live with $A D$ [4]. Generalized anxiety disorder (GAD) is one of the most common ADs [5, 6] and affects women twice as much as men [7]. European epidemiological studies have found a 12month prevalence of GAD of 1.7 to $3.4 \%$ [1] and a lifetime prevalence of 4.3 to $5.9 \%$ [8].

GAD is characterized by a persistent, excessive and exaggerated worry about everyday life events for no apparent reason [9]. Excessive worry is typically accompanied by an "on edge" feeling, muscular tension, chronic fatigue, and irritability that causes distress for at least 6 months, which impairs activities of daily living and decreases the quality of life $[5,9]$. Patients with GAD often live in a hyperalert state, scanning the environment for possible threats, whether real or perceived [7]. Patients with GAD have difficulty managing uncertainty given that they will often presume danger or threats without evidence of such [9]. Frequently, GAD is associated with other anxiety disorders (e.g., posttraumatic stress disorder or obsessive-compulsive disorder) and mood disorders [7, 10, 11] and shows a high correlation with depressive disorders $[1,12]$.

GAD is one of the most common mental disorders observed in primary care $(\mathrm{PC})$, with approximately $5 \%$ of people receiving $\mathrm{PC}$ services having a GAD diagnosis [12], and uses a significant amount of health resources despite the low recognition rate of the disorder [13]. People with GAD visit PC for physical somatic symptoms related to their anxiety disorders, such as headaches or backaches, gastrointestinal (e.g., dyspepsia), cardiovascular (e.g., palpitations) or respiratory (e.g., dyspnea) problems [14, 15]. Misdiagnosis of GAD in PC hinders the choice of appropriate treatment and health improvement $[8,16]$.

Available treatments for GAD include pharmacological and psychological interventions, either in isolation or in combination [17]. Selective serotonin reuptake inhibitors (SSRIs) are generally considered first-line treatments for GAD [17, 18]. Serotonin-noradrenaline reuptake inhibitors (SNRIs) and pregabalin are also considered first- or second-line treatments. Cognitive behavioural therapy (CBT) is the psychological first-line treatment for GAD. Self-help, psychoeducational groups and applied relaxation are also recommended [18]. Acceptance-based behavioural therapy, meta-cognitive therapy, and adjunctive mindfulness-based cognitive therapy have also shown efficacy in treating GAD [17]. Recent guidelines also recommend a stepped-care model were primary care may have a stronger role in the care pathway of people with GAD. The 2 first steps of the care for GAD include, in the first place, the identification, assessment, active monitoring and referral for additional assessment and intervention, and, secondly, self-help that may be individual non-facilitated or facilitated, psychoeducational groups, self-help groups [19].

Qualitative findings can help to understand the effectiveness of interventions by providing information about the broader context that interventions are associated with and how individual characteristics may influence attitudes towards them. Qualitative evidence synthesis (QES) can shed light on how interventions can be implemented and how, for whom and in what contexts they work [20]. The QES presented here was conducted to inform the formulation of recommendations using the GRADE Evidence To Decision framework [21] to be included in clinical practice guidelines (CPGs) for the treatment of GAD in PC. The principal objective of our QES was to locate, appraise and synthesize qualitative evidence to understand the implementation of care and treatment options for people with GAD in PC and outpatient settings.

\section{Methods}

A QES was conducted following the guidance of the Cochrane Qualitative and Implementation Methods Group [22].

\section{Design}

The research question was defined using the SPICE format [23]: Setting, PC; Perspective, adults (> 18 years old) with GAD, their family members and caregivers, and 
healthcare professionals attending patients with GAD; Phenomenon of Interest, the implementation of care and treatment options; Comparison, inpatient mental health settings; Evaluation, experience and trajectory of care, acceptability, feasibility and impact on the equity of treatment options [22].

\section{Data sources and search strategy}

Initially, we performed an exploratory scoping review in PubMed; Google Scholar; and other sources of grey literature, such as the Departments of Health of the Autonomous Communities of Spain. Second, we searched the following databases for publications from 2008 to September 2020: MEDLINE (Ovid SP), EMBASE (Elsevier), CINAHL (EBSCOhost), WOS (Clarivate Analytics) and PsyArticles/PsyInfo (EBSCOhost). Search strategies were developed for each database in collaboration with a librarian and included controlled vocabulary $(\mathrm{MeSH}$ terms) together with free text terms around the following keywords: generalized anxiety disorder, primary health care and qualitative methodology. The search was limited to publications in English and Spanish. The search strategy used for EMBASE is available in Additional file 1. Reference lists of included papers were also searched for additional studies.

\section{Selection criteria}

Studies were included if they used qualitative methods for data collection (e.g., open, structured or semistructured interviews; focus group discussions; diaries; document analysis, open-ended survey questions; and observation) and data analysis (e.g., thematic analysis, framework analysis or grounded theory) and if they were conducted to inform the implementation of care and treatment options for people with GAD in PC. The study selection criteria proposed by the Cochrane Qualitative and Implementation Methods Group were used [20]. Due to the scarce available literature, to find an adequate size pool of relevant data, some studies with indirect relevance were included when they provided information for the implementation of care and treatment options for people with GAD in PC. Specifically, studies that included patients with $\mathrm{AD}$ or mental health problems or that were conducted in outpatient settings (community health and/or mental health units outside inpatient mental hospital settings) were included. Nonqualitative studies, mixed methods studies that did not separately report qualitative findings and studies in languages other than English or Spanish were excluded.

\section{Study selection process}

In the first phase, two reviewers independently screened the titles and abstracts of all references retrieved via the search strategy. Second, the same two reviewers independently assessed the full-text articles selected in the first step for inclusion. The final selection was made through discussion with the research team until consensus was reached based on the study eligibility criteria.

\section{Critical appraisal}

Two reviewers independently assessed the methodological quality of each included study using the Spanish version of the Critical Appraisal Skills Programme (CASPe) tool for qualitative studies [24]. Disagreements between reviewers were discussed by a third reviewer until consensus was reached. No papers were excluded from the review on the basis of quality.

\section{Data extraction and synthesis}

The QES was performed using a three-stage thematic synthesis process [23]. In the first stage, codes were inductively derived from the data through an iterative process of attributing codes to small sections of meaning within the text, moving back and forth among the studies and constantly comparing the assigned data and codes. Two reviewers independently coded each study using NVivo 12 software. The codebook was shared among the wider group of authors and agreed upon. Second, codes were grouped into logical and meaningful groups in a hierarchical tree structure to form descriptive themes and sub-themes. Finally, analytical themes were developed and examined by all authors until the themes were finalized. Only findings relevant to the treatment of GAD in primary care were synthesized.

We used the Confidence in the Evidence from Reviews of Qualitative Research (CERQual) framework to conduct a final assessment of the overall confidence of the evidence $[22,25]$. The identified themes were presented in tables with descriptions of the following characteristics: 1) Summary of the findings, 2) Studies contributing to the review findings, 3) Methodological limitations, 4) Relevance, 5) Coherence, 6) Adequacy, and 7) Evaluation of confidence in each finding. The confidence in each finding was rated as high, moderate, low, or very low. The evaluation of relevance took into account whether the findings were totally or partially indirectly related to GAD based on the study populations and settings.

\section{Results}

\section{Summary of the selected studies}

After 3503 records were screened and the references of the included studies were checked, 12 full-text articles were included in the review (see Fig. 1 PRISMA diagram). Three of these 12 studies were additional studies identified and included after manually expanding the literature search. Table 1 shows the main characteristics of the 12 included studies. 


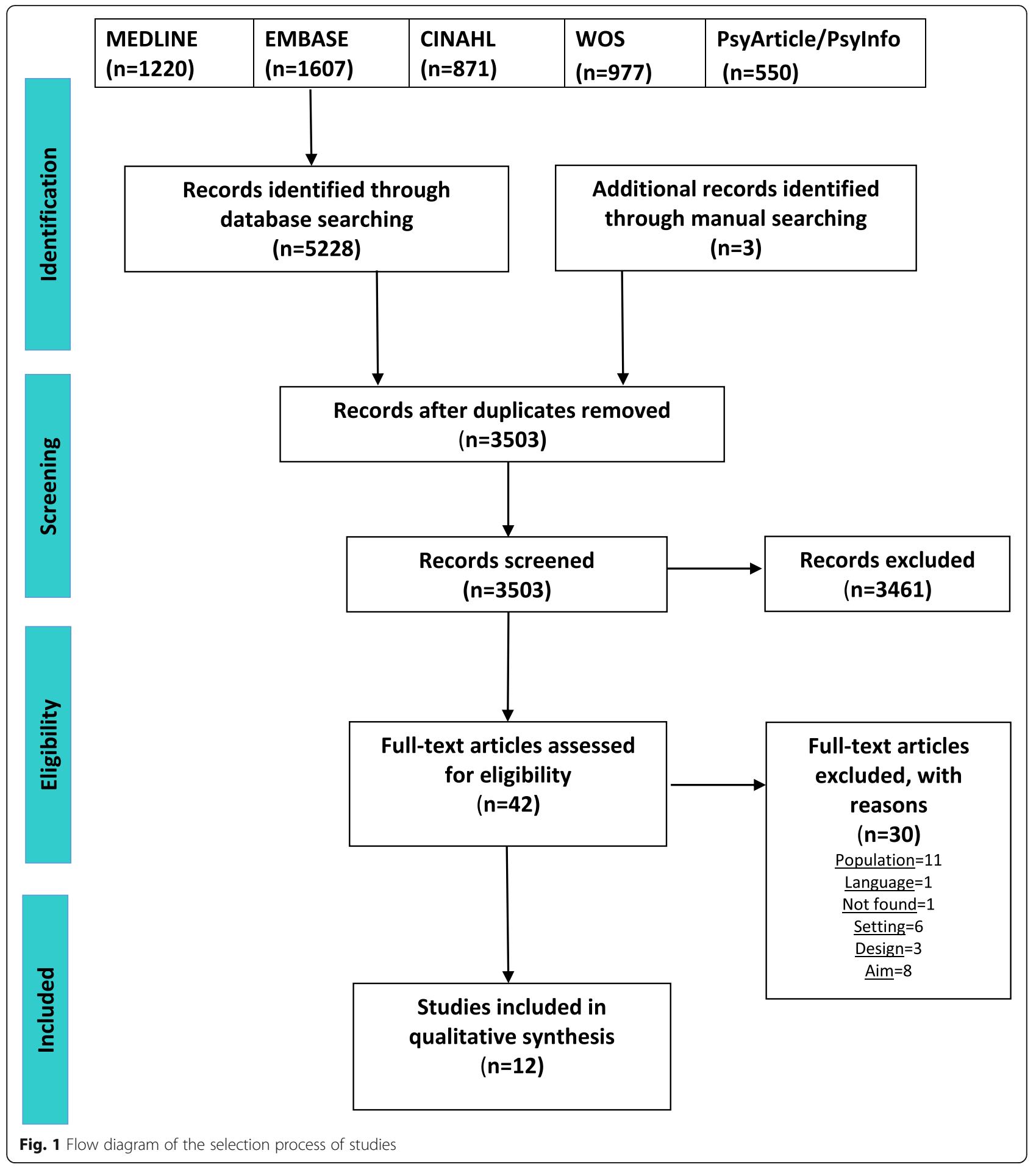

\section{Country}

Of the 12 included studies, 3 were carried out in Spain [26-28], 2 were carried out in the UK [29, 30], 3 were carried out in Canada [31-33], 1 was carried out in Sweden [34], 1 was carried out in the Netherlands [35], 1 as carried out in Ireland [36] and 1 was carried out in the United States [37].

\section{Objective}

Seven studies [26, 27, 31-34, 36] reported patients' experiences with GAD and their attitudes towards medication and psychotherapy. Three others [29, 30, 35] included both patients' and professionals' perspectives and their attitudes towards medication and psychotherapy, and one study described 
Table 1 Characteristics of the studies

\begin{tabular}{|c|c|c|c|c|c|}
\hline $\begin{array}{l}\text { Author, } \\
\text { year and } \\
\text { country }\end{array}$ & Aim of the study & Qualitative study design & Sample $(n)$ & Setting & $\begin{array}{l}\text { Methodological limitations } \\
\text { (CASPe) }\end{array}$ \\
\hline $\begin{array}{l}\text { Amor } 2018 \\
\text { Spain }\end{array}$ & $\begin{array}{l}\text { Include the point of view of } \\
\text { a group of patients with } \\
\text { GAD in the preparation of } \\
\text { the recommendations of a } \\
\text { clinical practice guideline. }\end{array}$ & $\begin{array}{l}\text { Focus groups and content } \\
\text { analysis. The testimonies of } \\
\text { users were linked to } \\
\text { recommendations based } \\
\text { on the evidence, with both } \\
\text { sources of information } \\
\text { placed at the same level of } \\
\text { relevance. }\end{array}$ & $\begin{array}{l}\text { Patients with } \\
\text { GAD (10). }\end{array}$ & $\begin{array}{l}\text { Community mental } \\
\text { health unit, Malaga- } \\
\text { Center, University Re- } \\
\text { gional Hospital of } \\
\text { Malaga. }\end{array}$ & $\begin{array}{l}\text { The design and use of } \\
\text { qualitative methodology is } \\
\text { adequate, but the objectives } \\
\text { are not clearly defined; the } \\
\text { methodological objectives } \\
\text { are mixed with the research } \\
\text { objectives. The presentation } \\
\text { of main findings could have } \\
\text { been more detailed. }\end{array}$ \\
\hline $\begin{array}{l}\text { Berg } 2010 \\
\text { Sweden }\end{array}$ & $\begin{array}{l}\text { Understand how people } \\
\text { experience body } \\
\text { psychotherapy focused on } \\
\text { affect for one year and to } \\
\text { investigate whether } \\
\text { treatment improves people's }\end{array}$ & Semi-structured interviews. & $\begin{array}{l}\text { Patients with } \\
\text { GAD (61). }\end{array}$ & $\begin{array}{l}\text { Psychiatric service, } \\
\text { intervention performed } \\
\text { by physiotherapists. }\end{array}$ & $\begin{array}{l}\text { The design and use of } \\
\text { qualitative methodology is } \\
\text { adequate. There are no } \\
\text { ethical considerations or } \\
\text { reflexive analyses. }\end{array}$ \\
\hline
\end{tabular}

ability to redefine their

somatic symptoms in a

broader psychosocial

context.

Bosman Understand the motivations

2016 Holland of people and GPs for the long-term use of antidepressants and possible ways to prevent unnecessary use.

Button 2019 Examine the experience of Canada patient with GAD about

(Toronto) Cognitive Behaviour Therapy (CBT) or Motivational Interviewing (MI).

Cook 2007 Understand the factors that USA influence the chronic use of (Philadelphia) benzodiazepines in older adults.
Semi-structured interviews in depth and constant comparative analysis.

Semi-structured interviews.

Patients with GAD and/or depression and $>6$ months of antidepressant use (30). GPs (20)

Patient with GAD (10)

Semi-structured interviews. GPs (33)

Patients with GAD or depression $(17)^{*}$ perceptions of men regarding the support they receive in groups and understand the role of professionals in access to these services.

Dickinson 2010 United Kingdom

CPG GAD elaboration group 2008 Spain

Explore the attitudes of older people and their general practitioners regarding the long-term use of antidepressant drugs and their experiences with the influences of the long-term use of these drugs.

Collect as much information as possible about the experiences of people with the disease and their relationship with the health system. observations. Se

Group discussion with patients and in-depth interviews with PC and specialist health professionals.
Patients with AD PC. and depression aged $\geq 75$ years (36) GPs (10)

Patients with AD, Health areas of the GPs, psychiatrists Community of Madrid. and psychologists (not reported)

PC.

de

PC network of the Amsterdam Medical Center of the University of $\mathrm{VU}$ and University Medical Center of Groningen.

Different places in Toronto.

PC.

Community services of The design and use of the town hall.

The design and use of qualitative methodology is adequate. There are no ethical considerations or reflexive analyses.

The design and use of qualitative methodology is adequate. Neither ethical considerations nor reflexive analyses are presented

The design and use of qualitative methodology seems to be adequate and to meet the minimum aspects of methodological quality. There are no ethical considerations or reflexive analyses. qualitative methodology is adequate. The presentation of the results obtained is also adequate. A section on ethical issues is included, but reflexivity is not assessed.

The design and use of qualitative methodology is adequate. The findings are clearly stated. Neither ethical considerations nor reflexive analyses are presented.

The design and use of qualitative methodology is adequate, but the objectives and analysis are not clearly defined. The findings are clearly stated. Neither ethical considerations nor reflexive analyses are presented. 
Table 1 Characteristics of the studies (Continued)

\begin{tabular}{|c|c|c|c|c|c|}
\hline $\begin{array}{l}\text { Author, } \\
\text { year and } \\
\text { country }\end{array}$ & Aim of the study & Qualitative study design & Sample $(n)$ & Setting & $\begin{array}{l}\text { Methodological limitations } \\
\text { (CASPe) }\end{array}$ \\
\hline $\begin{array}{l}\text { Quality } \\
\text { Ontario } 2017 \\
\text { Canada } \\
\text { (Ontario) }\end{array}$ & $\begin{array}{l}\text { values, needs, impacts and } \\
\text { preferences of those who } \\
\text { have experience with major } \\
\text { depressive disorder and GAD } \\
\text { and the psychological } \\
\text { treatments for these } \\
\text { disorders. The focus of } \\
\text { treatment was CBT, } \\
\text { interpersonal therapy and } \\
\text { supportive therapy. }\end{array}$ & & $\begin{array}{l}\text { GAD and/or } \\
\text { depression (20) }\end{array}$ & Canada. & $\begin{array}{l}\text { qualitative methodology is } \\
\text { adequate. Neither ethical } \\
\text { considerations nor reflexive } \\
\text { analyses are presented. }\end{array}$ \\
\hline $\begin{array}{l}\text { Hurtado } \\
2020 \text { Spain }\end{array}$ & $\begin{array}{l}\text { Understand the experience } \\
\text { and perceptions of people } \\
\text { diagnosed with GAD, along } \\
\text { their trajectory through } \\
\text { health services and their role } \\
\text { through the decision-making } \\
\text { process for their treatment. }\end{array}$ & Focus group. & $\begin{array}{l}\text { Patient with GAD } \\
\text { (24) }\end{array}$ & $\begin{array}{l}\text { Service of Mental } \\
\text { Health of the Regional } \\
\text { University Hospital of } \\
\text { Malaga and in the } \\
\text { Health Care Area Norte } \\
\text { de Córdoba. }\end{array}$ & $\begin{array}{l}\text { The design and use of } \\
\text { qualitative methodology is } \\
\text { adequate. Neither ethical } \\
\text { considerations nor reflexive } \\
\text { analyses are presented. }\end{array}$ \\
\hline $\begin{array}{l}\text { Marcus } 2011 \\
\text { Canada }\end{array}$ & $\begin{array}{l}\text { Identify how people perceive } \\
\text { the motivational interview } \\
\text { process before CBT. }\end{array}$ & Semi-structured interviews. & $\begin{array}{l}\text { Patients with } \\
\text { GAD (8) }\end{array}$ & $\begin{array}{l}\text { Private psychological } \\
\text { service. }\end{array}$ & $\begin{array}{l}\text { The design and use of } \\
\text { qualitative methodology is } \\
\text { adequate; no answers are } \\
\text { given to the questions that } \\
\text { were raised at the beginning } \\
\text { of the study. It is not explicit } \\
\text { if a coding strategy in pairs } \\
\text { was used to minimize the } \\
\text { bias of the researchers. } \\
\text { Neither ethical } \\
\text { considerations nor reflexive } \\
\text { analyses are presented. }\end{array}$ \\
\hline $\begin{array}{l}\text { O'Brien } 2017 \\
\text { Ireland }\end{array}$ & $\begin{array}{l}\text { Describe the possible } \\
\text { difficulties that a group of } \\
\text { participants may have in the } \\
\text { context of emotion-focused } \\
\text { therapy. }\end{array}$ & $\begin{array}{l}\text { Observations based on } \\
\text { multiple case studies. }\end{array}$ & $\begin{array}{l}\text { Patients with } \\
\text { GAD (14) }\end{array}$ & $\begin{array}{l}\text { PC psychology } \\
\text { services. }\end{array}$ & $\begin{array}{l}\text { The use of qualitative } \\
\text { methodology is adequate, } \\
\text { except in the design of the } \\
\text { data collection. Therapeutic } \\
\text { sessions are analysed, but } \\
\text { there is no description of } \\
\text { how they are carried out. A } \\
\text { possible source of bias is } \\
\text { that the analysis is } \\
\text { conducted based on a } \\
\text { theoretical framework } \\
\text { previously constructed by } \\
\text { one of the authors who } \\
\text { trained the others in its } \\
\text { application in the review of } \\
\text { the data. }\end{array}$ \\
\hline
\end{tabular}

* CBT: Cognitive Behavioural Therapy; CPG GAD: Clinical Practice Guidelines for the Management of Patients with GAD in Primary Care; GAD: Generalized Anxiety Disorder; AD: Anxiety Disorder, GP: General Practitioner; PC: Primary Care; MI: Motivational Interviewing; $n=$ sample size

professionals' and patients' experiences with GAD and the healthcare system [28]. The last study [37] included only the perspective of physicians regarding the chronic use of medication among elderly people.

\section{Data collection technique}

Most of the included studies used interviews, mainly semi-structured interview [29-35, 37]; 2 studies employed focus groups [26, 27], and one study was based on a case study [36].

\section{Setting}

Four studies were conducted in PC [30, 35-37], four studies were conducted in outpatient mental health services [26-28, 34], one study was conducted in municipal community services [29], one study was conducted in metropolitan outpatient psychiatric services [32], and two studies was carried out in a non-specified outpatient setting $[31,33]$.

\section{Population}

Six studies included only patients with GAD [26, 27, 31, 32, 34, 36], while another study included general 
practitioners (GPs) [37]. The rest of the studies included a combined sample of patients with GAD, anxiety disorders or depression and GPs [29, 30, 33, 35]. One study explored only male patients, one study [29] also included psychiatrists and psychologists [28], and two studies included exclusively older people's perspectives [30,37].

\section{Integrated themes}

Based on the synthesis of the qualitative evidence, the findings were organized under the following themes: (1) Trajectory of care, (2) Information needs, (3) Acceptability of, preferences for and implementation considerations for treatment options; and (4) Interruption of antidepressant treatment. The findings categorized under each theme and the confidence assessment for each finding are shown in Tables $2-5$.

\section{Theme 1: trajectory of care}

People with GAD might experience multiple episodes of the disorder over their lifetimes when facing long care trajectories $[28,35]$. The experience of constantly looking for treatments was common. Finding an accessible, adequate and effective treatment could make people with GAD become involved in a long process of searching for, accessing and changing different therapeutic options $[26,27,33]$.

The start of any new treatment tended to cause resistance and concern in patients with GAD due to the uncertainty. The degree of concern depended on previous knowledge of and the satisfaction or unsatisfaction previous experiences with different treatments. However, this initial concern tended to disappear over time [26, $28,33,34,36]$.

\section{Theme 2: information needs}

People with GAD expressed the need to receive more information about the disorder they suffered, the places where they could get help and the kind of help that was available [27, 30,33]. Additionally, a lack of information on treatment effectiveness was identified as a barrier [33].

Family members and caregivers who supported people with GAD were also interested in receiving information about the disorder, its management and what to do during a crisis. However, people with GAD did not always have or want this support, as the social or family context could sometimes be a source of concern $[27-29,35]$. GPs also had information needs; specifically, they expressed doubts about how to act during anxiety crises and relapses [28, 35, 37].

\section{Theme 3: preferences for, acceptability of and implementation considerations for treatment options}

There was individual variability regarding treatment preferences. Some people with GAD preferred pharmacotherapy as a main treatment or as a complement to psychotherapy. However, others showed greater preferences for psychological treatments [26-28, 33]. Receiving the preferred treatment increased the perception of efficacy. Preferences and acceptability affected adherence to pharmacological or psychological treatments [27-29].

Five studies [29, 30, 33, 35, 36] examined experiences related to pharmacological treatment. Bosman et al. [35], Dickinson et al. [30], and Cook et al. [37] pointed out that the acceptability of a drug depended on the perceptions of both the patient and GP regarding its effectiveness for symptom relief. The acceptability of a drug was reduced when people with GAD perceived that it had a limited long-term capacity to eliminate their health problems [27]. Drugs were well accepted if GAD was thought to stem primarily from a physical or medical cause rather than a psychological cause [30].

Some people expressed few or no concerns when starting pharmacological treatment, while others rejected drugs and refused to take them, as they were worried about their side effects and the stigma associated with their use [32, 33, 35, 37].

GPs tended to recognize that social and emotional problems required nonpharmacological interventions that they could not always provide and expressed discomfort when prescribing a drug in those situations [30].

People with GAD reported both positive and negative experiences with psychological therapies [31, 33, 34]. The acceptability of psychological therapies depended on people's previous experiences [33, 34]. Nevertheless, some people with GAD expressed a strong preference for psychological treatment [27]. Empathy, trust and honesty facilitated acceptance and adherence to these therapies [31, 32, 34, 35]. Characteristics such as distrust, pessimism or directive and judgmental stile were highlighted as negative experiences [31,33], while involve mutual efforts and engagement by both therapist and patient were positive experiences [31].

In addition, contextual characteristics such as comfort with the environment and therapeutic space were well evaluated by patients with GAD and influenced the acceptability of psychotherapy [32]. The most accepted relationships with health care professionals were with clinical psychologists, especially if they had specialized training and therapeutic experience [32,33]. One study analysed an intervention conducted by physiotherapists, with whom patients' relationships seemed to be more variable [34].

People with GAD differed in the type of preferred psychotherapy. CBT, interpersonal therapy and group support or therapy were perceived to be more effective than other types of psychotherapy [27, 28, 33]. Only one study analysed experience with CBT and Motivational interview (MI) [31], though none of the included studies 
analysed experiences interpersonal therapy. Group support and group therapies were valued as positive experiences, as they allowed the development of social support networks and helped people overcome social isolation $[27,29]$.

Motivational interviews (MIs) were found to be an acceptable form of therapy [32]. The application of four MIs sessions before CBT increased awareness, impulsiveness, motivation, and confidence for the CBT psychological intervention. Characteristics such as an increase in self-awareness about a problem, a reduction in symptoms of anxiety and worry, and more concrete thoughts about how to manage their conditions were aspects highlighted by the interviewees with GAD. When MIs were performed, a positive relationship with the therapist was a relevant success factor for the therapy [32]. The integration of CBT-MIs, allowed people with GAD to assume a more active and engaged role in treatment. Tools and strategies to cope with worry (i.e., thought record, relaxation, behavioural experiments) were necessary conditions for acceptability of MI-CBT or CBT [31].

Emotion-focused therapy (EFT) was evaluated in one study [36]. The acceptability of EFT depended on the patient's interpersonal difficulty expressing emotions [36]. GAD patients' experiences and reported acceptability of affect-focused body psychotherapy (ABP) was variable [36]. The acceptability of ABP was related to the previous experiences that people had with their own bodies and their ability to open up to new therapies [34]. Some people with GAD reported that the therapy increased their stress levels, while other patients reported difficulties finding the connection between concrete situations in their lives and feeling their bodies become tense [36]. However, other GAD patients managed to integrate the perceptions of their own body with their experiences and emotions, allowing them to reconceptualize their bodily sensations as signs of meaning and not as generators of anxiety [36].

\section{Theme 4: interruption of antidepressant treatment}

None of the included studies analysed barriers to adherence to or voluntary interruption of antidepressant treatment.

The interruption of antidepressant treatment is not usually systematized in PC. Practices related to treatment interruption were very variable depending on the GP and his or her relationship with the person with anxiety $[30,33,37]$. Medication was either passively or actively maintained by the GP. Factors affecting the passive maintenance of medication were inertia, routinization and forgetfulness [32, 37]. Active medication maintenance was based on an assessment of the risk/benefit balance performed by GPs and patients that reflected the value of continuing with the medication in view of the perceived benefits [30, 35, 37].

Perception of functional improvements such as a reduction in anxiety symptoms, improved sleep or increased stability were the basis of doctors' and patients' preferences to maintain antidepressant treatment [30, $35,37]$. Likewise, possible dependence on or abuse of these drugs was a factor that was viewed negatively [30, 35]. In some cases, antidepressants were the only available treatment, and the GP refused to interrupt the patient's use of them due to a lack of access to other therapeutic alternatives [30].

One of the factors that hindered the interruption of pharmacological treatment was relapse. Relapse after attempting to stop treatment reinforced patients' and GPs' decisions to continue the use of medication [30, 35, 37]. However, one article pointed out that relapses can be a consequence of continuous, uninterrupted treatment [30]. Older patients could have additional barriers to interrupting pharmacological treatment, such as pessimism due to the chronicity of the disease [30]. However, GPs perceived that people of advanced age had a lower risk of drug addiction [30].

When planning to interrupt medication, both GPs and GAD patients tried to identify a suitable time in terms of the patient's stability and an appropriate reason to start the interruption of treatment [35]. An automated reminder could help GPs start the process of interrupting medication. An appointment specifically scheduled to review the long-term use of antidepressants allowed renegotiation of the treatment plan, including interruption [35].

Both GPs and patients reported needing information about the recommended duration of antidepressant treatments and reasons that should guide their discontinuation. In addition, they also needed information about treatment effectiveness and potential associated side effects in the short and long term. Specifically, information about the possibility and symptoms of dependence as well as about the expected effects associated with medication withdrawal was needed [30, $35,37]$.

\section{Discussion}

The findings indicate that the trajectory of care for people with GAD is long and fluctuates over time, involving multiple difficulties in accessing and maintaining initial treatment or successive treatment options. The literature also reports low remission and high relapse rates over long follow-up periods [38]. The remission rate was reported to be approximately $0.38 \%$ after five years of prospective follow-up [39]. More than $74 \%$ of GAD patients continued to have symptoms after tracking them for 12 years [40]. Additionally, 25\% of GAD patients who 
stopped treatment relapsed within 1 month, and up 80\% relapsed within 1 year [41]. More information on the disorder and its treatment options is needed both for GP and GAD patients and their carers. Better awareness and information materials on GAD may facilitate both early appropriate diagnosis and long-term care. The early detection of $\mathrm{AD}$ in $\mathrm{PC}$ should be improved, as a recent study shows that only $25 \%$ of cases are correctly identified in the PC setting [42].

The Evidence to Decision framework includes the analysis of acceptability, feasibility and impact on the equity of treatment options [43]. Acceptability aspects can be broadly informed by this review. The findings of our review show that there is wide variability in preferences for and the acceptability of different treatment options. The variable acceptability of treatment options can be a barrier to feasibility and continuity of care, as it affects uptake and adherence to treatment and probably attendance of PC. Difficulty accepting new treatments among people with GAD can hinder the trajectory of care and may require patients to be informed about stepped care pathways before the initiation of treatment [44] to allow them to be prepared to try a number of treatment options until the most effective treatment for them is found. Acceptability also varies over time, which is probably related to high treatment dropout, especially in pharmacological treatments. For example, the dropout rate of SSRIs is between 18 and 30\% [45] and is associated with a high risk of relapse [46]. Considering these conclusions, our findings only provide partial information regarding feasibility. There is a lack of rich qualitative data on long-term care, adherence and the adverse effects of pharmacological treatments. Findings from included studies were not able to discriminate experiences and acceptability of different types of antidepressants. Meanwhile, planned interruption has been discussed in depth but there is still a debate on the duration of pharmacological treatments [45].

The lack of clinical psychologists in primary may also impact the access and referral to recommended psychotherapies. In most western countries, psychotherapies are less used than medication regardless of preferences [47]. In our review only in 2 studies, both from Spain, [27, 28], the lack of access to psychotherapy was mentioned as a barrier to care by people with GAD. We have not included it as a finding as it was not triangulated in other contexts. Nevertheless, countries as Norway and the United Kingdom are starting programs to improve access to psychological treatments in PC by increasing the number of clinical psychologists [47] or training GPs in Internetbased-CBT [48]. Hopefully, these initiatives may impact on increasing feasibility of guideline implementation.
Our review provides information for efforts to improve the care of people with GAD in PC through interventions for patient empowerment and person-centred care. The elicitation of preferences for treatment options and the trade-offs they imply may improve adherence, as has been tested for other health conditions [49].

Issues related to the impact of treatment options on equity were also not explored in depth in the included studies. Our review found some specific evidence for elderly people with GAD, but an analysis of the acceptability of, preferences for and impact of treatment options by gender was not possible with the available data. Nevertheless, this QES only partially examined how social determinants of health affect the trajectories of people with GAD, taking into account that the prevalence of GAD is higher between the ages of 24 and 65, in women than in men (ratio 2:1), in people with lower incomes, in unemployed people, in women who perform domestic work and in people without a partner $[1,50]$. Additionally, a metasynthesis of qualitative evidence for mental health interventions in $\mathrm{PC}$ found inequalities in treatment access affecting vulnerable groups (e.g., migrants, asylum seekers, long-term unemployed people, homeless people, and elderly people with depression) [51].

The CERQual approach allowed us to improve the transparency of and confidence in the findings based on the decisions made in the review process. Findings with high and very high levels of confidence can support clinical practice guidelines (CPGs) and other evidence-based documents that use the GRADE framework to include aspects such as patient acceptability, values and preferences, as well as implementation considerations [43]. Findings with low confidence levels may require additional supporting evidence.

Other aids that provide information to improve the empowerment of patients are CPGs. CPGs incorporate the values and preferences of the population and consider factors such as equity, acceptability and feasibility to determine the strength of recommendations based on the elaboration of patient decision aids (DAs) [47]. DAs are helpful for facilitating shared decision making in the shift towards a person-centered model and adapting population-based recommendations into individual patient-directed recommendations [52]. In addition, the development of DAs derived from CPG recommendations could offer a unique opportunity to improve clinical practice and increase patient satisfaction in the decision-making process related to their health and treatments [53].

\section{Limitations}

The number of papers available (to us) was limited due to lack of funding and time constraints. Only Spanish and English papers could be reviewed due to a lack of 
funding for translation. This QES included studies published between 2008 and 2018, so we could only summarize the most recent scientific evidence to inform the treatment of people with GAD in PC, in which we identified qualitative research needs in addition to the abovementioned needs. The experiences and preferences of people with GAD with respect to recommended treatment options such as CBT, the stepped care model or combinations of pharmaceutical treatment and psychotherapy have been recently analysed sparsely or not at all.

Searching other databases or sources of grey literature search may also have found additional studies. To address the lack of available literature, indirect data were included in the review if they could inform the research question.

\section{Conclusions}

Initial resistance to new treatments among people with GAD can make it difficult for them to access and adhere to treatment. Improving care may require patients to be informed of possible trajectories in stepped care pathways before the initiation of treatment so they are aware that they may need to try a number of options until the most effective treatment for them is found. Increased awareness of and information materials on GAD may facilitate both appropriate diagnosis and long-term care.

\section{Supplementary Information}

The online version contains supplementary material available at https://doi. org/10.1186/s12875-020-01307-6.

Additional file 1.

\begin{abstract}
Abbreviations
AD: Anxiety Disorder; ABP: Affect-focused Body Psychotherapy; CASPe: Critical Appraisal Skills Programme; CERQual: Confidence in the Evidence from Reviews of Qualitative Research; CBT: Cognitive Behavioural Therapy; CPG: Clinical Practice Guideline; CPGs: Clinical Practice Guidelines; DAs: Decision Aids; EFT: Emotion-Focused Therapy; GP: General Practitioner; GPS: General Practitioners; GAD: Generalized Anxiety Disorder; GRADE: Grading of Recommendations, Assessment, Development and Evaluation; PC: Primary Care; QES: Qualitative Evidence Synthesis; MI: Motivational Interview; SSRIs: Selective Serotonin Reuptake Inhibitors; SNRIs: Serotonin-Noradrenaline Reuptake Inhibitors; WHO: World Health Organization
\end{abstract}

\section{Acknowledgements}

The authors are grateful for the collaboration of Estefania Herrera Ramos in the design and preparation of the search strategy and Carlos González Rodríguez for his technical support.

\section{Authors' contributions}

AT, ATC and VR designed the study. AT and VR wrote the initial manuscript draft. LP, PS, MM, and WP advised the implementation of the study and contributed to writing the manuscript. All authors made substantial contributions to the revision of the manuscript and approved the final version.

\section{Funding}

This qualitative systematic review was carried out as part of an effort to update the clinical practice guidelines for the treatment of generalized anxiety disorder in primary care financed by the Ministry of Health,

Consumer Affairs and Social Welfare in the annual work plan (2018) of the Spanish Network of Agencies for the Evaluation of Health Technologies and Benefits of the National Health System.

Availability of data and materials

All data and materials can be accessed upon request to the corresponding author.

Ethics approval and consent to participate

Not applicable.

\section{Consent for publication \\ Not applicable.}

\section{Competing interests}

The authors declare that they have no competing interests.

\section{Author details}

${ }^{1}$ Canary Islands Health Research Institute Foundation, Tenerife, Spain. ${ }^{2}$ Research Network on Health Services in Chronic Diseases (REDISSEC), Madrid, Spain. ${ }^{3}$ Center for Biomedical Research of the Canary Islands (CIBICAN), Tenerife, Spain. ${ }^{4} T$ he Spanish Network of Agencies for Health Technology Assessment and Services of the National Health System (RedETS), Tenerife, Spain. ${ }^{5}$ Facultad de Ciencias de la Salud - Sección de Psicología, University of La Laguna, Tenerife, Spain. ${ }^{6}$ Unidad de Apoyo a la Investigación, Gerencia Asistencial de Atención Primaria, Madrid, Spain.

${ }^{7}$ Department Preventive Medicine and Public Health, University Rey Juan Carlos, Madrid, Spain. ${ }^{8}$ Evaluation Unit (SESCS), Canary Islands Health Service (SCS), Tenerife, Spain.

Received: 2 December 2019 Accepted: 9 November 2020 Published online: 20 November 2020

\section{References}

1. Wittchen HU, Jacobi F, Rehm J, Gustavsson A, Svensson M, Jönsson B, et al. The size and burden of mental disorders and other disorders of the brain in Europe 2010. Eur Neuropsychopharmacol. 2011;21(9):655-79 Available from: https://linkinghub.elsevier.com/retrieve/pii/S0924977X11001726.

2. Kessler RC, Berglund P, Demler O, Jin R, Merikangas KR, Walters EE. Lifetime Prevalence and Age-of-Onset Distributions of DSM-IV Disorders in the National Comorbidity Survey Replication. Arch Gen Psychiatry. 2005;62(6): 593 Available from: http://archpsyc.jamanetwork.com/article.aspx?doi=10.1 001/archpsyc.62.6.593.

3. Chisholm D, Sweeny K, Sheehan P, Rasmussen B, Smit F, Cuijpers P, et al. Scaling-up treatment of depression and anxiety: a global return on investment analysis. Lancet Psychiatry. 2016;3(5):415-24 Available from: https://linkinghub.elsevier.com/retrieve/pii/S2215036616300244.

4. World Health Organization. Mental health in the workplace [Internet]. WHO. World Health Organization; 2017 [cited 2020 May 22]. Available from: https://www.who.int/mental_health/es/.

5. Locke AB, Kirst NSC. Diagnosis and management of generalized anxiety disorder and panic disorder in adults. Am Fam Physician. 2015;19(9):617-24.

6. Angst J, Gamma A, Baldwin DS, Ajdacic-Gross V, Rössler W. The generalized anxiety spectrum: prevalence, onset, course and outcome. Eur Arch Psychiatry Clin Neurosci. 2009;259(1):37-45 Available from: http://link. springer.com/10.1007/s00406-008-0832-9.

7. Baldwin D. Generalized anxiety disorder in adults: Epidemiology, pathogenesis, clinical manifestations, course, assessment, and diagnosis UpToDate [Internet]. 2018 [cited 2019 Oct 22]. Available from: https://www. uptodate.com/contents/generalized-anxiety-disorder-in-adultsepidemiology-pathogenesis-clinical-manifestations-course-assessment-anddiagnosis.

8. Wittchen $\mathrm{H}-\mathrm{U}$, Jacobi F. Size and burden of mental disorders in Europe-a critical review and appraisal of 27 studies. Eur Neuropsychopharmacol. 2005 Aug;15(4):357-76 Available from: https://linkinghub.elsevier.com/retrieve/pii/ S0924977X05000751. 
9. American Psychiatric Association. Diagnostic and Stadistical Manual of Mental Disorders: DSM-V. (5th ed). Fifth Edit Washington, DC: American Psychiatric Association; 2013.

10. Meuldijk D, Carlier IVE, van Vliet IM, van Veen T, Wolterbeek R, van Hemert AM, et al. The clinical effectiveness of concise cognitive behavioral therapy with or without pharmacotherapy for depressive and anxiety disorders; a pragmatic randomized controlled equivalence trial in clinical practice. Contemp Clin Trials. 2016;47:131-8 Available from: https://linkinghub. elsevier.com/retrieve/pii/S1551714415301531.

11. den Boeft M, Twisk JWR, Terluin B, Penninx BWJH, van Marwijk HWJ, Numans ME, et al. The association between medically unexplained physical symptoms and health care use over two years and the influence of depressive and anxiety disorders and personality traits: a longitudinal study. BMC Health Serv Res. 2016;16(1):100 Available from: http://bmchealthservres. biomedcentral.com/articles/10.1186/s12913-016-1332-7.

12. Tyrer $P$, Seivewright $H$, Johnson T. The Nottingham Study of Neurotic Disorder: predictors of 12-year outcome of dysthymic, panic and generalized anxiety disorder. Psychol Med. 2004;34(8):1385-94 Available from: http://www.ncbi.n/m.nih.gov/pubmed/15724870.

13. Wittchen H-U, Kessler RC, Beesdo K, Krause P, Höfler M, Hoyer J. Generalized anxiety and depression in primary care: prevalence, recognition, and management. J Clin Psychiatry. 2002;63(Suppl 8):24-34 Available from: http://www.ncbi.nlm.nih.gov/pubmed/12044105.

14. Stein MB, Sareen J. Generalized Anxiety Disorder. Solomon CG, editor. N Engl J Med [Internet] 2015 Nov 19;373(21):2059-68. Available from: http:// www.nejm.org/doi/10.1056/NEJMcp1502514

15. García-Campayo J, Caballero F, Perez M, López V. Prevalence and clinical features of newly diagnosed generalized anxiety disorder patients in Spanish primary care settings: the GADAP study. Actas Esp Psiquiatr. 2012:40(3):105-13 Available from: http://www.ncbi.n/m.nih.gov/pubmed/22723129.

16. Roy-Byrne PP, Wagner A. Primary care perspectives on generalized anxiety disorder. J Clin Psychiatry. 2004;65(Suppl 1):20-6 Available from: http://www. ncbi.nlm.nih.gov/pubmed/15384933.

17. Katzman MA, Bleau P, Blier P, Chokka P, Kjernisted K, Van Ameringen M. Canadian clinical practice guidelines for the management of anxiety, posttraumatic stress and obsessive-compulsive disorders. BMC Psychiatry. 2014;14(Suppl 1):S1 Available from: http://bmcpsychiatry.biomedcentral. com/articles/10.1186/1471-244X-14-S1-S1.

18. National Institute for Health and Care Excellence (NICE). Generalised anxiety disorder and panic disorder in adults: management [Internet]. 2019 [cited 2020 May 3]. Available from: https://www.nice.org.uk/guidance/cg113/ chapter/1-Guidance\#stepped-care-for-people-with-gad.

19. National Health Institute for Health and Care Excellence (NICE). Common mental health problems: identification and pathways to care [Internet]. 2011 [cited 2020 Sep 13]. Available from: https://www.nice.org.uk/guidance/ cg123/chapter/1-Guidance.

20. Noyes J, Booth A, Cargo M, Flemming K, Garside R, Hannes K, et al. Cochrane Qualitative and Implementation Methods Group guidance series_paper 1: introduction. J Clin Epidemiol. 2018:97:35-8 Available from: https://linkinghub.elsevier.com/retrieve/pii/S0895435617313537.

21. Guyatt GH, Oxman AD, Schünemann HJ, Tugwell P, Knottnerus A. GRADE guidelines: a new series of articles in the journal of clinical epidemiology. J Clin Epidemiol. 2011;64(4):380-2 Available from: https://linkinghub.elsevier. com/retrieve/pii/S089543561000329X.

22. Lewin S, Bohren M, Rashidian A, Munthe-Kaas H, Glenton C, Colvin CJ, et al. Applying GRADE-CERQual to qualitative evidence synthesis findings-paper 2: how to make an overall CERQual assessment of confidence and create a Summary of Qualitative Findings table. Implement Sci. 2018;13(S1):10 Available from: https://implementationscience.biomedcentral.com/articles/1 0.1186/s13012-017-0689-2.

23. Thomas J, Harden A. Methods for the thematic synthesis of qualitative research in systematic reviews. BMC Med Res Methodol. 2008;8(1):45 Available from: https://bmcmedresmethodol.biomedcentral.com/articles/1 0.1186/1471-2288-8-45

24. CASP. Critical Appraisal Skills Programme (CASP). Qualitative Appraisal Checklist for Qualitative Research [Internet]. 2006. Available from: http:// www.casp-uk.net/wp-content/uploads/2011/11/.

25. Moberg J, Oxman AD, Rosenbaum S, Schünemann HJ, Guyatt G, Flottorp S, et al. The GRADE Evidence to Decision (EtD) framework for health system and public health decisions. Heal Res Policy Syst. 2018;16(1):45 Available from: https://health-policy-systems.biomedcentral.com/articles/10.1186/s12 961-018-0320-2.

26. Hurtado MM, Villena A, Vega A, Amor G, Gómez C, Morales-Asencio JM. 'I have anxiety, but I have values and preferences' experiences of users with generalized anxiety disorder: a qualitative study. Int J Ment Health Nurs. 2020;29(3):521-30.

27. Amor G, Vega A, Villena A, Gómez-Ocaña C, Morales-Asencio JM, Hurtado MM. Implicación de usuarios diagnosticados de Trastorno de Ansiedad Generalizada en la elaboración de una guía de práctica clínica. Univ Psychol. 2018;17(2):1-10 Available from: http://revistas.javeriana.edu.co/index.php/ revPsycho/article/view/15684.

28. Grupo de Trabajo de la Guía de Práctica Clínica para el Manejo de Pacientes con Trastornos de Ansiedad en Atención Primaria. Guía de Práctica Clínica para el Manejo de Pacientes con Trastornos de Ansiedad en Atención Primaria. Madrid. Plan Nacional para el SNS del MSC. Unidad de Evaluación de Tecnologías Sanitarias. Agencia Laín Entralgo: Guías de Práctica Clínica en el SNS: UETS No 2006/10; 2008; 2008.

29. Cramer H, Horwood J, Payne S, Araya R, Lester H, Salisbury C. Do depressed and anxious men do groups? What works and what are the barriers to help seeking? Prim Health Care Res Dev. 2014;15(03):287-301 Available from: http://www.journals.cambridge.org/abstract_S1463423613000297.

30. Dickinson R, Knapp P, House AO, Dimri V, Zermansky A, Petty D, et al. Longterm prescribing of antidepressants in the older population: a qualitative study. Br J Gen Pract. 2010;60(573):e144-55 Available from: http://bjgp.org/ lookup/doi/10.3399/bjgp10X483913.

31. Button ML, Norouzian N, Westra HA, Constantino MJ, Antony MM. Client reflections on confirmation and disconfirmation of expectations in cognitive behavioral therapy for generalized anxiety disorder with and without motivational interviewing. Psychother Res. 2019;29(6):723-36.

32. Marcus $M$, Westra $H$, Angus $L$, Kertes $A$. Client experiences of motivational interviewing for generalized anxiety disorder: a qualitative analysis. Psychother Res. 2011;21(4):447-61 Available from: http://www.tandfonline. com/doi/abs/10.1080/10503307.2011.578265.

33. Health Quality Ontario. Psychotherapy for major depressive disorder and generalized anxiety disorder: a health technology assessment. Ont Heal Technol Assess Ser. 2017;17(15):1-167 Available from: http://www.hqontario.ca/ evidence-to-improve-care/journal-ontario-health-technology-assessment-series.

34. Berg AL, Sandahl C, Bullington J. Patients' perspective of change processes in affect-focused body psychotherapy for generalised anxiety disorder. Body Mov Danc Psychother. 2010;5(2):151-69 Available from: https://www. tandfonline.com/doi/full/10.1080/17432979.2010.494853.

35. Bosman RC, Huijbregts KM, Verhaak PF, Ruhé $H G$, van Marwijk HW, van Balkom AJ, et al. Long-term antidepressant use: a qualitative study on perspectives of patients and GPs in primary care. Br J Gen Pract. 2016; 66(651):e708-19 Available from: http://bjgp.org/lookup/doi/10.3399/bjgp16 X686641.

36. O'Brien K, O'Keeffe N, Cullen H, Durcan A, Timulak L, McElvaney J. Emotionfocused perspective on generalized anxiety disorder: a qualitative analysis of clients' in-session presentations. Psychother Res. 2019;29(4):524-40 Available from: https://www.tandfonline.com/doi/full/10.1080/10503307.2017.1373206.

37. Cook JM, Marshall R, Masci C, Coyne JC. Physicians' perspectives on prescribing benzodiazepines for older adults: a Qualitative study. J Gen Intern Med. 2007;22(3):303-7 Available from: http://link.springer.com/10.1 007/s11606-006-0021-3.

38. Pollack MH. Refractory generalized anxiety Disorder. J Clin Psychiatry. 2009; 70(suppl 2):32-8 Available from: http://www.psychiatrist.com/abstracts/ abstracts.asp?abstract=2009s02/s020906.htm.

39. Yonkers KA, Dyck IR, Warshaw M, Keller MB. Factors predicting the clinical course of generalised anxiety disorder. Br J Psychiatry. 2000;176(6):544-9 Available from: https://www.cambridge.org/core/product/identifier/ S0007125000154625/type/journal_article.

40. Bruce SE, Yonkers KA, Otto MW, Eisen JL, Weisberg RB, Pagano M, et al. Influence of psychiatric comorbidity on recovery and recurrence in generalized anxiety Disorder, social phobia, and panic Disorder: a 12-year prospective study. Am J Psychiatry. 2005;162(6):1179-87 Available from: http://psychiatryonline.org/doi/abs/10.1176/appi.ajp.162.6.1179.

41. Rickels KSE. The clinical course and long-term management of generalized anxiety disorder. J Clin Psychopharmacol. 1990;10(3 Suppl):101S-10S.

42. Piontek K, Shedden-Mora MC, Gladigau M, Kuby A, Löwe B. Diagnosis of somatoform disorders in primary care: diagnostic agreement, predictors, and comaprisons with depression and anxiety. BMC Psychiatry. 2018;18(1): 
361 Available from: https://bmcpsychiatry.biomedcentral.com/articles/10.11 86/s12888-018-1940-3

43. Welch VA, Akl EA, Guyatt G, Pottie K, Eslava-Schmalbach J, Ansari MT, et al. GRADE equity guidelines 1: considering health equity in GRADE quideline development: introduction and rationale. J Clin Epidemiol. 2017;90:59-67 Available from: https:/linkinghub.elsevier.com/retrieve/pii/S0895435617303396.

44. National Institute for Health and Clinical Excellence. Generalised anxiety disorder in adults: Evidence Update [Internet]. 2019 [cited 2019 Nov 11]. Available from: https://www.nice.org.uk/guidance/cg113/evidence/ evidence-update-pdf-136336573.

45. Mochcovitch MD, da Rocha Freire RC, Garcia RF, Nardi AE. Can long-term pharmacotherapy prevent relapses in generalized anxiety Disorder? A systematic review. Clin Drug Investig. 2017;37(8):737-43 Available from: http://link.springer.com/10.1007/s40261-017-0528-x.

46. Culpepper L. Generalized anxiety Disorder and medical illness. J Clin Psychiatry. 2009;70(suppl 2):20-4 Available from: http://www.psychiatrist. com/abstracts/abstracts.asp?abstract=2009s02/s020904.htm.

47. Clark DM. Realizing the mass public benefit of evidence-based psychological therapies: the IAPT program. Annu Rev Clin Psychol. 2018; 14(1):159-83.

48. Wilhelmsen M, Høifødt RS, Kolstrup N, Waterloo K, Eisemann M, Chenhall R, et al. Norwegian general practitioners' perspectives on implementation of a guided web-based cognitive behavioral therapy for depression: a Qualitative study. J Med Internet Res. 2014;16(9):e208.

49. Abraham N, Street R, Castillo D, Deswal A, Richardson P, Hartman C, et al. Complex antithrombotic therapy: determinants of patient preference and impact on medication adherence. Patient Prefer Adherence [Internet]. 2015 Nov;1657. Available from: https:/www.dovepress.com/complexantithrombotic-therapy-determinants-of-patient-preference-and\%2D\%2 Dpeer-reviewed-article-PPA.

50. Ruscio AM, Chiu WT, Roy-Byrne P, Stang PE, Stein DJ, Wittchen H-U, et al. Broadening the definition of generalized anxiety disorder: effects on prevalence and associations with other disorders in the National Comorbidity Survey Replication. J Anxiety Disord. 2007;21(5):662-76 Available from: https:// linkinghub.elsevier.com/retrieve/pii/S088761850600168X.

51. Lamb J, Bower P, Rogers A, Dowrick C, Gask L. Access to mental health in primary care: a qualitative meta-synthesis of evidence from the experience of people from 'hard to reach' groups. Heal An Interdiscip I Soc Study Heal IIIn Med. 2012 Jan 25;16(1):76-104 Available from: http://journals.sagepub. com/doi/10.1177/1363459311403945.

52. van der Weijden T, Boivin A, Burgers J, Schünemann HJ, Elwyn G. Clinical practice guidelines and patient decision aids. An inevitable relationship. J Clin Epidemiol. 2012;65(6):584-9 Available from: https://linkinghub.elsevier. com/retrieve/pii/S0895435611003234.

53. Perestelo Pérez L, Salcedo Fernández F, Toledo Chávarri A, Álvarez Pérez Y, Vicente Edo M, Abt Sacks A, et al. Desarrollo de herramientas de ayuda para la toma de decisiones compartida derivadas de las recomendaciones de las guías de práctica clínica. Ministerio de Sanidad, Servicios Sociales e Igualdad. Servicio de Evaluación del Servicio Canario de la Salud; 2017. Informes de Evaluación de Tecnologías Sanitarias.; 2017.

\section{Publisher's Note}

Springer Nature remains neutral with regard to jurisdictional claims in published maps and institutional affiliations.

\section{Ready to submit your research? Choose BMC and benefit from}

- fast, convenient online submission

- thorough peer review by experienced researchers in your field

- rapid publication on acceptance

- support for research data, including large and complex data types

- gold Open Access which fosters wider collaboration and increased citations

- maximum visibility for your research: over $100 \mathrm{M}$ website views per year

At $\mathrm{BMC}$, research is always in progress.

Learn more biomedcentral.com/submissions 